\title{
High-Speed Buried Tunnel Junction VCSELs with High Operation Temperature
}

\author{
- Invited Paper -
}

\author{
Werner Hofmann \\ Dept. of Electrical Engineering and Computer Sciences, University of California at Berkeley, CA 94720, USA \\ Phone: +1(510)643-5801, Fax:+1(510)643-1878, Email: whofmann@eecs.berkeley.edu
}

\begin{abstract}
$1.55-\mu \mathrm{m}$ vertical-cavity surface-emitting lasers with reduced parasitics and superior modulation bandwidth in excess of $10-\mathrm{GHz}$ at $85^{\circ} \mathrm{C}$ are realized. Bit-rates of $17-\mathrm{Gb} / \mathrm{s}$ are demonstrated at room temperature, and error-free $12.5-\mathrm{Gb} / \mathrm{s}$ is achieved up to $85^{\circ} \mathrm{C}$.
\end{abstract}

\section{Introduction}

High-Speed vertical-cavity surface-emitting lasers (VCSEL) with internal bandwidths exceeding $20 \mathrm{GHz}$ have been presented recently emitting in the near infrared spectrum [1-2]. As this waveband can only be used for short distances up to $300 \mathrm{~m}$, there has been a great effort in developing long-wavelength, high-speed VCSELs with steady progress [3-7].

Especially, long-wavelength VCSELs with buried tunnel junction (BTJ) have shown promising results and recordhigh modulation bandwidths.

In the near future, the market demands cost-effective 100G Ethernet solutions. Consequently, higher laser bandwidth is demanded for the projected data-rates, favourably provided by a cost-effective device at long wavelengths and high temperatures that range up to $85^{\circ} \mathrm{C}$ for uncooled operation.

In this paper we present high-speed long-wavelength BTJ VCSELs with superior bandwidths up to $85^{\circ} \mathrm{C}$.

\section{Low Parasitics Design}

The lasers under investigation were grown by molecular beam epitaxy on InP substrate. The high-speed $1.55 \mu \mathrm{m}$ VCSEL structure is an improved version of the device described in [4], with optimized active region, detuning, mirror-reflectivities and doping levels. The schematic layout of the laser chip is shown in Fig. 1. BCB is used as low-dielectric constant passivation, eliminating contact pad capacitances. For high laser bandwidth and sufficient gain at elevated temperatures, the active region is composed of 7 heavily strained ( $2.5 \%$ compressive strain, pseudomorphic) InAlGaAs quantum wells near the borderline of critical layer thickness. For the presented device, the threshold current was designed to be lowest at $60^{\circ} \mathrm{C}$ heat-sink temperature. This was achieved by a large mode-gain offset resulting in negative $T_{0}$ values. Due to the BTJ, which allows the elimination of nearly all $p$-conducting material with higher electrical resistances and optical losses, a

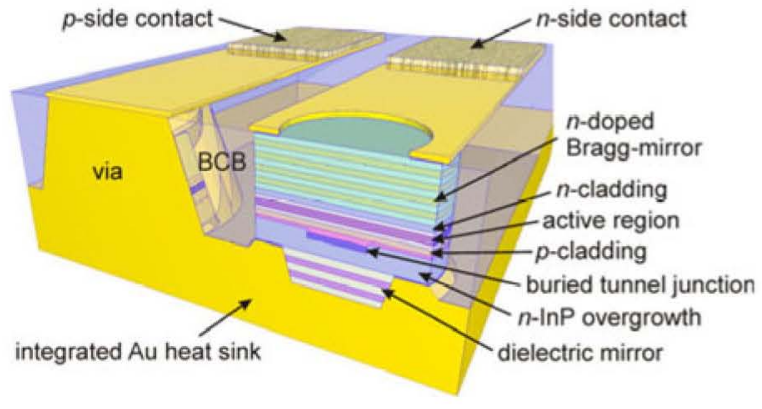

Fig. 1. Schematic cross-section of a high-speed $1.55 \mu \mathrm{m}$ InPbased BTJ VCSEL. The device is mounted epi-down on an electroplated gold pseudo-substrate. The InP substrate is removed while manufacturing. Both $n$ - and $p$-contact can be accessed on top. Contact-pad capacitances are minimized.

differential series resistance as low as $40-50 \Omega$ has been achieved, impedance matched to electrical drivers.

As the parasitic response of our VCSELs can be well modeled by a first-order equivalent circuit [5], a threepole filter function including relaxation-oscillation frequency $f_{R}$, intrinsic damping $\gamma$ and parasitic roll-off $f_{p}$ describes the response of our VCSEL well, allowing several intrinsic parameters, to be extracted. Constant terms in Eq. (1) are the differential quantum efficiencies $\eta_{d}$ of laser and detector.

$$
H(f)=\eta_{d, L} \eta_{d, P D} \cdot \frac{f_{R}^{2}}{f_{R}^{2}+j \frac{\gamma}{2 \pi} f-f^{2}} \cdot \frac{1}{1+j \frac{f}{f_{P}}}
$$

Even though our devices in reference design [4] showed excellent high-speed behaviour for small chip diameters, the bandwidth of devices with larger semiconductor chips were still clearly limited by device parasitics. By reducing the doping levels of the blocking diode next to the BTJ from 5 to $1 \cdot 10^{17} \mathrm{~cm}^{-3}$, the parasitic capacitance was significantly lowered, boosting the modulation bandwidth from below $7 \mathrm{GHz}$ to $9 \mathrm{GHz}$.

\footnotetext{
Modulation Performance

VCSELs are characterized by very high carrier and photon densities in the optical resonator causing a damped modulation response. Consequently, low parasitics are especially important for VCSELs as the smaller relaxation oscillation overshoot cannot compensate a parasitic roll-off. In Fig. 2, a supcrior modulation per-
} 


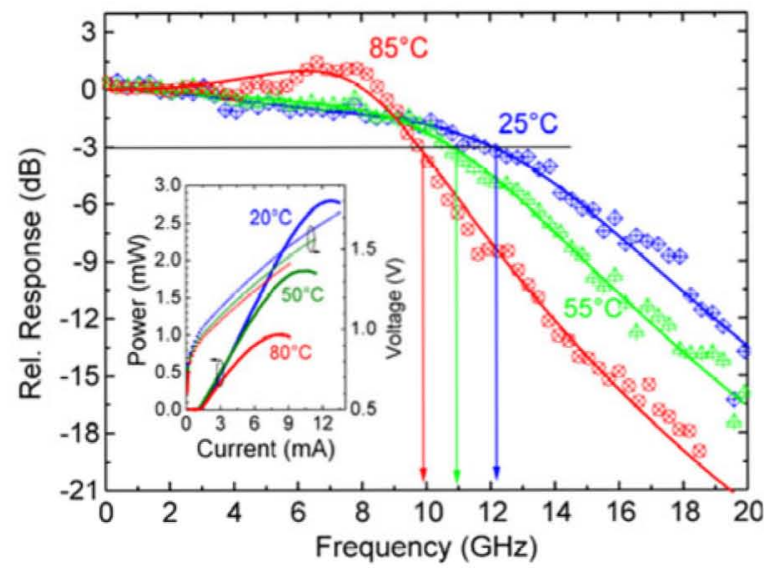

Fig. 2. Small-signal modulation performance of $1.55 \mu \mathrm{m}$ VCSEL with improved modulation bandwidth and temperature range. At $25^{\circ} \mathrm{C}$ modulation bandwidth in excess of $12 \mathrm{GHz}$ can be stated and even at elevated temperatures of $85^{\circ} \mathrm{C}$ $10 \mathrm{GHz}$ modulation bandwidth is available. Scatters: measured data; solid lines: fit to Eq.1. LIV-characteristics given as inset.

formance can be identified over a wide temperature range. The $3-\mathrm{dB}$ bandwidth exceeds $12 \mathrm{GHz}$ at $25^{\circ} \mathrm{C}$, is $11 \mathrm{GHz}$ at $55^{\circ} \mathrm{C}$ and $10 \mathrm{GHz}$ at $85^{\circ} \mathrm{C}$. The $L I V$-performance is given as an inset showing more than $2.5 \mathrm{~mW}$ at room temperature and $1 \mathrm{~mW}$ at $80^{\circ} \mathrm{C}$. A detailed investigation of intrinsic laser parameters clearly demonstrated a lowered $K$-factor from 0.4 to $0.3 \mathrm{~ns}$, yielding an improvement of the damping limit [6]. With a shortened laser cavity, photon lifetimes could be further reduced yielding a $15-\mathrm{GHz}$ bandwidth [7].

\section{Large-Signal Performance}

The VCSELs presented here were especially designed for uncooled operation with superior and constant rating rather than peak-performance at a certain fixed temperature. As demonstrated in Fig. 3, error-free data-transmission at $12.5-\mathrm{Gb} / \mathrm{s}$ up to $85^{\circ} \mathrm{C}$ is feasible. Open eyes at 12.5 and $17-\mathrm{Gb} / \mathrm{s}$ clearly state the potential for $100 \mathrm{G}$ Ethernet applications.

\section{Conclusions}

In this paper we present our $1.55 \mu \mathrm{m}$ BTJ-VCSELs with improved high-speed and high-temperature performance. Internal parasitics have been drastically reduced by redesign of doping-levels. Modulation bandwidth at $5 \mathrm{~mA}$ is sufficient for $12.5-\mathrm{Gb} / \mathrm{s}$ over a temperaturerange from $0-85^{\circ} \mathrm{C}$ at output powers around $1 \mathrm{~mW}$. Internal relaxation oscillation frequencies could also be improved by higher differential material gain from highly strained quantum-wells. At room temperature we present a record-high modulation bandwidth above $12 \mathrm{GHz}$ demonstrating data-rates of $17-\mathrm{Gb} / \mathrm{s}$ for $100 \mathrm{G}$ Ethernet.

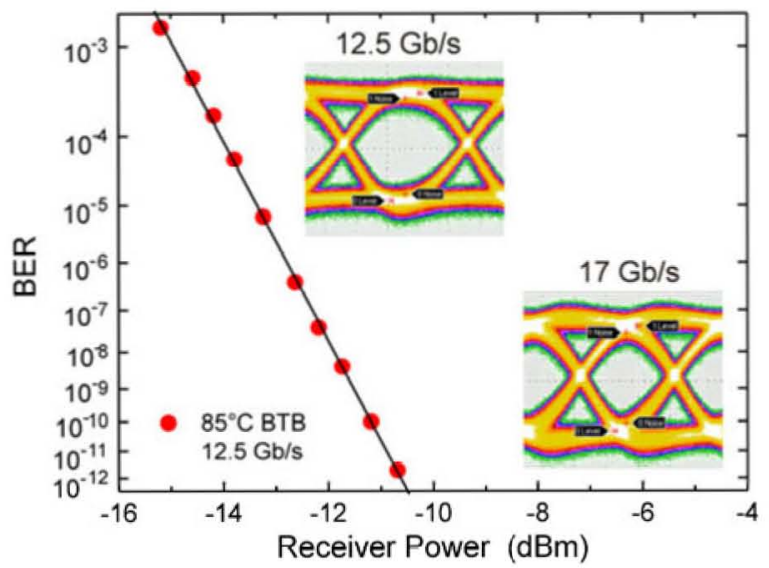

Fig. 3. Large-Signal modulation performance of the VCSEL presented in Fig. 2. Error-free data-transmission at $12.5-\mathrm{Gb} / \mathrm{s}$ at $85^{\circ} \mathrm{C}$ is demonstrated. ( $2^{7}-1$ PRBS, BTB). Inset eye diagrams recorded at 12.5 and $17-\mathrm{Gb} / \mathrm{s}$ data-rates are both wide open. Eye diagrams were recorded at $25^{\circ} \mathrm{C}$.

\section{Acknowledgements}

These results were achieved at the Walter Schottky Institute, Technical University of Munich with Prof. Markus-Christian Amann. We appreciative the contribution of the co-workers Michael Müller and Gerhard Böhm in device fabrication and crystal growth, respectively. Large-signal characterization was done at the Technical University of Berlin with the help of Prof. Dieter Bimberg's group. Device mapping and die handling was done in collaboration with Vertilas $\mathrm{GmbH}$, Germany. We gratefully acknowledge the DAAD (German Academic Exchange Service) for granting a research fellow-ship for Dr. Hofmann to continue his research on VCSELs at UC Berkeley in the group of Prof. Chang-Hasnain.

\section{References}

1. P. Westbergh et al., "Large aperture $850 \mathrm{~nm}$ VCSELs operating at bit rates up to $25 \mathrm{Gbit} / \mathrm{s}$ ", Electron. Lett., 44, (2008), pp. 907-908.

2. F. Hopfer et al., " $20 \mathrm{~Gb} / \mathrm{s} 85{ }^{\circ} \mathrm{C}$ error-free operation of VCSELs based on submonolayer deposition of quantum dots", IEEE J. Sel. Topics Quantum Electron., 13, (2007) pp. 1302-1308.

3. A. Syrbu et al., "10 Gbps VCSELs with High Single Mode Output in $1310 \mathrm{~nm}$ and $1550 \mathrm{~nm}$ Wavelength Bands" OFC/NFOEC 2008, OThS2.

4. W. Hofmann et al., "Long-wavelength vertical-cavity surface-emitting lasers for high-speed applications and gas sensing", IET Optoelectron., 2, (2008) pp. 134-142.

5. M.-C. Amann et al., "InP-based long-wavelength VCSELs and VCSEL arrays", IEEE J. Sel. Topics Quantum Electron., to be published in 2009.

6. W. Hofmann et al., "1.55 $\mu \mathrm{m}$ VCSEL with Enhanced Modulation Bandwidth and Temperature Range", IEEE Photonics Technol. Lett., to be published in 2009.

7. M. Müller et al., " $1.55 \mu \mathrm{m}$ InP-based Short-Cavity-VCSELs with Enhanced Modulation-Bandwidths of $15 \mathrm{GHz}$ ", to be presented at ECOC (invited), Vienna, 2009. 